\title{
The need for aquatic tracking networks: the Permanent Belgian Acoustic Receiver Network
}

\author{
Jan Reubens ${ }^{1 *} \mathbb{D}$, Pieterjan Verhelst ${ }^{1,2,3} \mathbb{D}$, Inge van der Knaap ${ }^{1,2}$, Benny Wydooghe ${ }^{1}$, Tanja Milotic ${ }^{3} \mathbb{C}$, \\ Klaas Deneudt ${ }^{1}$ (I), Francisco Hernandez ${ }^{1}$ and Ine Pauwels ${ }^{3}$ (1)
}

\begin{abstract}
Aquatic biotelemetry techniques have proven to be valuable tools to generate knowledge on species behaviour, gather oceanographic data and help in assessing effects from anthropogenic disturbances. These data types support international policies and directives, needed for species and habitat conservation. As aquatic systems are highly interconnected and cross administrative borders, optimal data gathering should be organized on a large scale. This need triggered the development of regional, national and international aquatic animal tracking network initiatives around the globe. In Belgium, a national acoustic receiver network for fish tracking, called the Permanent Belgian Acoustic Receiver Network, was set up in 2014 with different research institutes collaborating. It is a permanent network with 160 acoustic receivers and since the start, over 800 animals from 16 different fish species have been tagged and generated more than 17 million detections so far. To handle all the (meta)data generated, a data management platform was built. The central database stores all the data and has an interactive web interface that allows the users to upload, manage and explore (meta)data. In addition, the database is linked to an R-shiny application to allow the user to visualize and download the detection data. The permanent tracking network is not only a collaborative platform for exchange of data, analysis tools, devices and knowledge. It also creates opportunities to perform feasibility studies and Ph.D. studies in a cost-efficient way. The Belgian tracking network is a first step towards a Pan-European aquatic tracking network.
\end{abstract}

Keywords: Tracking, Network, Database, Aquatic biotelemetry, European tracking network, Permanent Belgian Acoustic Receiver Network

\section{Background}

Telemetry is an increasingly applied method to investigate the behavioural ecology of aquatic animals in the wild. Multiple biotelemetry techniques are available to track aquatic animals and generate detailed spatiotemporal observations of their movements (e.g. dispersion, migration and homing) and habitat use. This information is needed to understand ecosystem functioning and dynamics. The biotelemetry techniques have already proven to provide cost-efficient crucial oceanographic

*Correspondence: jan.reubens@vliz.be

${ }^{1}$ Flanders Marine Institute, Wandelaarkaai 7, 8400 Ostend, Belgium

Full list of author information is available at the end of the article data [1], help in assessing the effects of anthropogenic disturbance by, for instance, man-made constructions [2-4] and thus deliver the necessary insights supporting management, restoration and conservation aquatic species and habitats [5-7]. The resulting data and knowledge form the scientific basis of international policies and directives for species and habitat conservation [8-10], such as the European Common Fisheries Policy and the Integrated Maritime Policy, Natura 2000, Marine Strategy Framework Directive and the Water Framework Directive, among others (http://ec.europa.eu/envir onment/index_en.htm).

Aquatic systems are highly interconnected, linking different environments to one another and enable species 
to move over large distances, crossing human-imposed administrative borders. This has triggered the development of large-scale regional, national and international tracking network initiatives around the globe (e.g. the Florida Acoustic Telemetry network (FACT) in the United States [11], the animal tracking facility of the Integrated Marine Observing System (IMOS) in Australia [12] and the Ocean Tracking Network (OTN) in Canada [13]). Each network not only entails the development and maintenance of physical networks of devices, but also the set-up of collaborative platforms for data exchange, analysis tools, devices and knowledge. Clearly, these coordinated, large-scale and integrated approaches offer the users valuable opportunities to: (1) scale-up the study area and questions at stake by improving data gathering and sharing among stakeholders; (2) increase funding opportunities; and (3) encourage industry commitment to ensure compatibility between brands and technologies $[8,9]$.

In Belgium, scientists collaborated in the set-up of a permanent acoustic receiver network for fish tracking, by merging several local networks of smaller fish tracking projects of different institutes. Here, we discuss the rationale behind the network, the current status and data-flow, the opportunities and the integration in a European tracking network.

\section{The Belgian tracking network Rationale}

The Belgian tracking network resulted from a collaboration between Ghent University, the Research Institute for Nature and Forest (INBO) and the Flanders Marine Institute (VLIZ) in the framework of LifeWatch (http://lifew atch.eu/).

The LifeWatch consortium, which was established in 2012 as part of the European Strategy Forum on Research Infrastructure (ESFRI), works as a virtual laboratory and is meant to support biodiversity research, for climatological and environmental impact studies, to support the development of ecosystem services and to provide information for policy makers in Europe. This large European research infrastructure consists of several biodiversity observatories, databases, web services and modelling tools. It integrates the existing systems, upgrades them and develops new systems. Since 2017, LifeWatch is fully operational and will run for at least 20 years, aiming at long-term series of observation data.

As part of the Belgian contribution to LifeWatch, a national marine-freshwater observatory, hereafter called the Permanent Belgian Acoustic Receiver Network (PBARN), was established (http://www.lifewatch. be/) to track fish in their natural environment. The Belgian tracking network includes the physical network of acoustic receivers (i.e. PBARN) and a data management system. The latter includes a database, a data portal (http://www.lifewatch.be/etn) and a data explorer (http:// rshiny.lifewatch.be/ETN data/).

\section{The physical network}

The PBARN consists of 160 permanently installed receivers: 31 in the Belgian part of the North Sea (BPNS); 64 in the Scheldt river basin (of which 39 in the Western Scheldt, and 25 in the Zeeschelde and Dijle), 53 in the Albert Canal, and 12 in the Meuse river (Fig. 1). The coverage of the permanent network allows tracking of fresh water, marine and diadromous fish in different environments, which are in a greater or lesser extent impacted by human activities. Studies on the permanent network involve $\mathrm{PhD}$ studies as well as government or internationally funded projects. The PBARN is, in times, augmented by temporary receiver networks. These networks are deployed in the framework of specific projects or studies with a more local focus (e.g. a wind farm, a river stretch, a marsh area). In these projects, higher resolution data or additional environments/geographical areas are required for the questions at stake. The number of receiver stations for the temporary projects, and the duration of their deployments depend on the project outline and duration. This manuscript focuses on the permanent network.

Different types of acoustic receivers of Vemco Ltd (Canada, Nova Scotia) are used (i.e. VR2W, VR2Tx, VR2C and VR2AR), and the type depends upon the environment and mooring opportunities. Receivers are moored on navigation buoys, ship wrecks, man-made structures (i.e. reefballs, wind turbines and shipping locks) and along river and canal banks. When attached to buoys, the receivers' hydrophones point downward. When attached to river or canal banks, the receivers are moored near the bottom in upward position. Depending on the type of mooring, the environment and the oceanographic and meteorological conditions, the detection probability of the receivers will differ. We refer to Reubens et al. [14] for detailed information on this issue.

Since the start of the network in 2014 almost 900 animals have been tagged. In total 811 animals of 16 species have been detected (Fig. 2): 151 Atlantic cod (Gadus morhua L.), 95 Atlantic salmon (Salmo salar L.), 2 common carp (Cyprinus carpio L.), 4 common dab (Limanda limanda G.), 3 European chub (Squalius cephalus L.), 401 European eel (Anguilla anguilla L.), 8 European flounder (Platichthys flesus L.), 3 European plaice (Pleuronectes platessa L.), 15 European seabass (Dicentrarchus labrax L.), 1 lemon sole (Microstomus kitt W.), 30 river lamprey (Lampetra fluviatilis L.), 2 sea lamprey (Petromyzon marinus L.), 10 Starry smooth-hound (Mustelus asterias C.), 40 Twaite shad (Alosa fallax L.), 6 common roach 


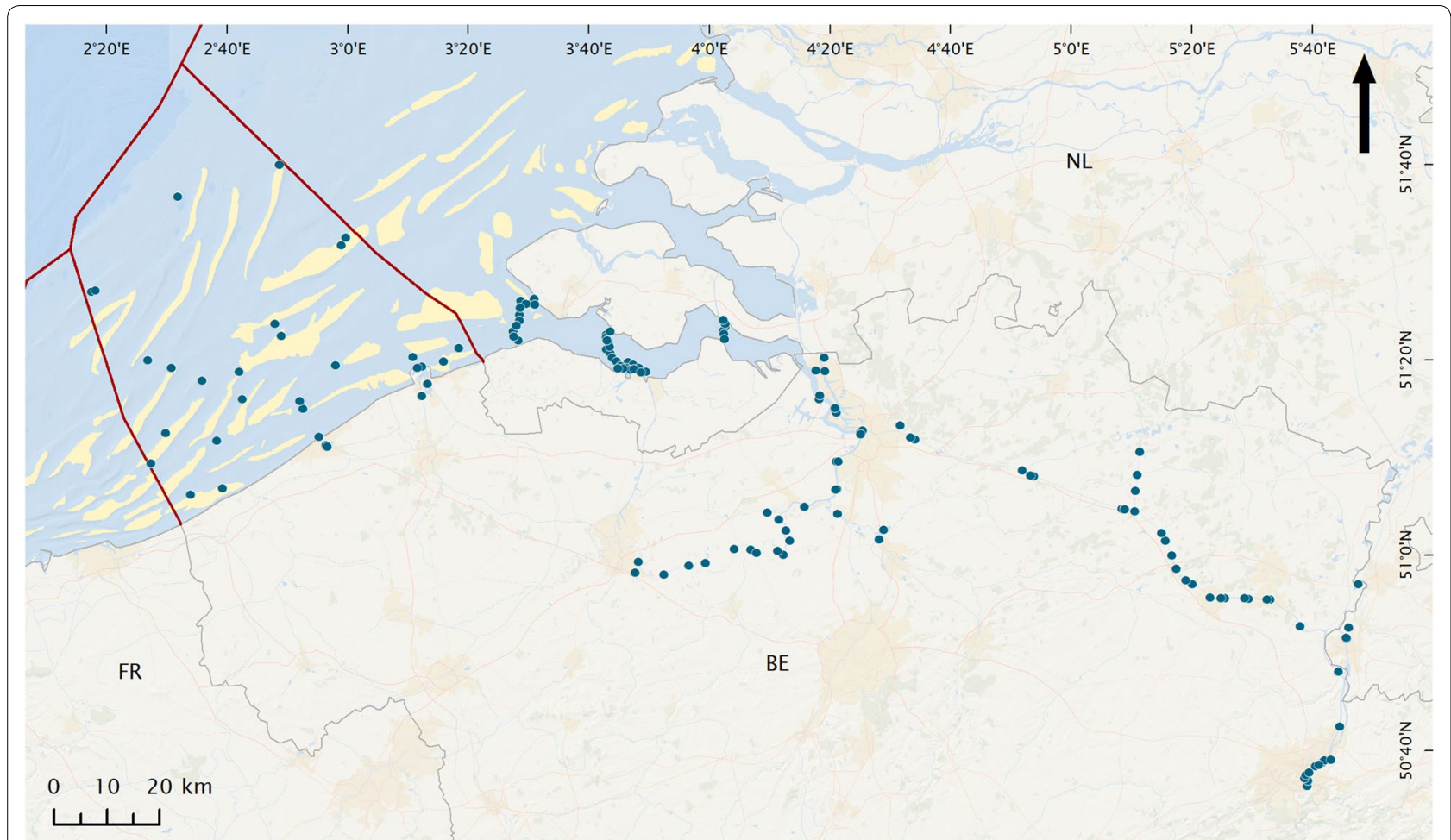

Fig. 1 The Permanent Belgian Acoustic Receiver Network. Each dot represents a receiver station. National borders are indicated with grey solid lines; the Belgian part of the North Sea are indicated with a red solid line

(Rutilus rutilus L.) and 20 welsh catfish (Silurus glanis B.). Several eels from acoustic telemetry projects in The Netherlands and Germany have been detected on the PBARN [15].

So far, the PBARN generated more than 17 million detections. Most of these detections occurred at receiver stations in the rivers, canals and the Western Scheldt estuary. This is, however, strongly correlated to the tagging location and number of specimens per species tagged. The BPNS, on the other hand, had most of the occurrences from eels tagged abroad [15]. These results indicate that each part of the PBARN renders valuable information.

\section{Data management}

Next to a physical network, proper data management is needed for a successful telemetry network. All data are stored in a central PostgreSQL database hosted by VLIZ. The database stores both the occurrences (i.e. detection data) and the metadata related to tags, animals, receivers, deployments and projects. An interactive online web interface (http://www.lifewatch.be/etn), developed in PHP using Symfony framework, gives access to all detection- and metadata stored in the database and allows to manage and explore it. The users have to upload detection and metadata into the database by themselves. This is not performed by a data management team. To ease this job, standard upload files (.csv) are available. In addition, several quality controls (QCs) are in place, to minimize the chance on human errors and maximize the data quality. These QCs are applied to the raw detections stored in the database. The QC algorithms monitor the correctness of the data (e.g. are there any detections before an animal was released). There is a data policy (see http://www.lifewatch.be/etn) with moratorium rules in place to ensure that (1) data ownership is protected and (2) data becomes open access to the public at large after the moratorium period ended. This data management platform will serve as the central data portal for the European Tracking Network (ETN) [16].

We refer to the manual (http://www.lifewatch.be/etn/ assets/docs/ETN-DataManual.pdf?1.0) for detailed information about the data management platform.

To explore, visualize and download the detection data an R-Shiny application was developed (http://rshiny.lifew atch.be/ETN data/).

\section{Opportunities}

In addition to the advantages mentioned in the "Background" section, the PBARN has proven to create 


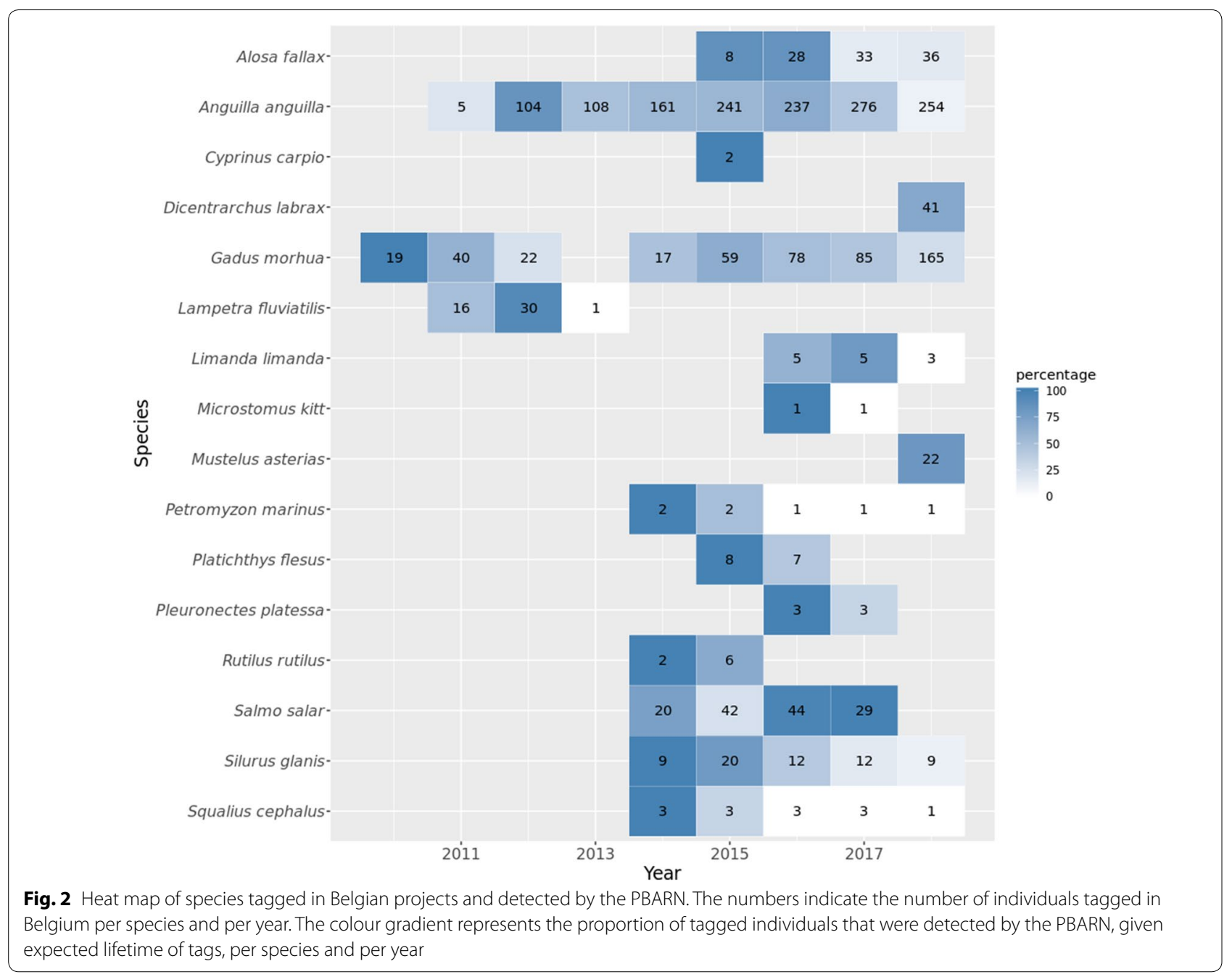

opportunities. One of these is the ability to perform a feasibility study in a cost-efficient way. For some species, it is difficult to assess whether acoustic telemetry will be the most suitable technique for a specific research question. With the presence of a network, a feasibility study can be performed with a limited number of acoustic tags. Such a study can render information on the type and amount of data that will be gathered, and on the geographical and temporal coverage. This can also aid the researchers to decide on number of receivers and tags needed and to place receivers at strategic points to maximize the detections of the species of interest. Breine et al. [17], for instance, could test a modified external tagging technique on twaite shad. Shads are very sensitive to handling and stress, rendering the species rather unsuitable for electronic tagging studies. However, the authors of this study succeeded in the development of an external attachment procedure for twaite shad. Through the availability of an extensive array of receivers in the Scheldt Estuary, this study could be performed with a limited amount of resources. Further, several pilot studies, which will use the PBARN, are currently initiated for European sea bass (Dicentrarchus labrax L.) and starry smooth-hound (Mustelus asterias C.). Similarly to pilot studies, the existence of the permanent network can aid Ph.D. studies, as the resources for Ph.D.s are often limited to a bench fee that does not allow to cover the equipment and logistics needed for large experimental set-ups. The PBARN reduces the equipment needs and costs related to logistics and maintenance. Three Ph.D. studies, making use of the PBARN, are currently ongoing: two on European eel $[4,15,18]$ and one on Atlantic cod.

Next to providing infrastructure, a coordinated network also stimulates cooperation between researchers on national and international level. In 2014 and 2015, European eels from different river catchments in Western Europe (i.e. Belgium, The Netherlands and Germany) were detected on the PBARN. Previously, it was assumed 
eels use the Nordic migration route over Scotland. However, the detections recorded by PBARN revealed that a noteworthy portion of the population uses a southern migration route. Although the different studies were independently organized and focused on different research questions, it resulted in a joint A1-publication [15], describing this novel insight in eel spawning migration. Another ongoing study on silver eel escapement in The Netherlands resulted, once again, in detections on the PBARN.

Further, not only infrastructure and data, but also expertise can be exchanged. Telemetry experts from Belgium are currently involved in several projects in The Netherlands and Germany (unpublished data).

\section{Towards a European tracking network}

The PBARN is a national showcase proving the value of coordinated networks. However, this national network is just a first step towards a larger, international aquatic telemetry network. Several large-scale initiatives are already active in different parts of the world (e.g. IMOS Animal Tracking in Australia, OTN in Canada, ATAP in South-Africa and GLATOS in the Great Lakes) [11, 1921]. These networks address crucial scientific, conservation and management questions on a larger scale.

So far, Europe was lagging behind in these large-scale initiatives. To meet the demand for a Pan-European aquatic telemetry network, ETN was launched in 2017 in the framework of the European project AtlantOS (https://www.atlantos-h2020.eu/). Recently, a COST (European Cooperation in Science and Technology) Action was granted (CA18102). COST is supported by the EU Framework Programme Horizon 2020 and the Action will connect biotelemetry users across Europe and beyond and will boost ETN towards a sustainable, efficient and integrated Pan-European biotelemetry network.

ETN is expected to make an important contribution to ensure compatibility between acoustic telemetry brands. The European telemetry scene is highly diverse, using multiple telemetric approaches and equipment from several brands. However, the different brands do not have any agreements regarding transmit protocols, ID allocation and tag serial numbers. This leads to the potential loss of data and tag code duplications. To move forward towards a European collaborative network that could provide relevant information in support of decision making, compatibility between brands and agreements on transmit protocols and ID allocation is imperative.

In addition, the data management system developed for PBARN will be used as the central data repository for ETN (http://www.lifewatch.be/etn). Necessary adaptations and extensions, required to cover European needs, were implemented recently and the system can now handle large amounts of data. With ETN, Europe will be positioned in the global arena of already existing aquatic telemetry network initiatives [16].

\section{Author's contributions}

$J R, I P, P V$, IvdK have conceptualized and written the manuscript and provided expertise on the telemetry opportunities in the North Sea. TM and BW provided expertise on data management processes. KD and FH coordinated the work and manage the LifeWatch project (which provided the funds for the Belgian acoustic receiver network). All authors read and approved the final manuscript.

\section{Author details \\ ${ }^{1}$ Flanders Marine Institute, Wandelaarkaai 7, 8400 Ostend, Belgium. ${ }^{2}$ Marine Biology Research Group, Ghent University, Krijgslaan 281, 9000 Ghent, Bel- gium. ${ }^{3}$ Research Institute for Nature and Forest (INBO), Havenlaan 88, Box 73, 1000 Brussels, Belgium.}

\section{Acknowledgements}

R. Baeyens, J.-P. Benitez, J. Breine, S. Bruneel, D. Buysse, A. Cattrijsse, J. Coeck, T. Deckmyn, N. De Maerteleire, S. Franquet, A. Debruyne, E. Gelaude, J. Goossens, Y. Jacobs, I. Lambeens, T. Lanssens, Y. Maes, A. Mouton, M. Ovidio, S. Pieters, K. Robberechts, T. Saerens, R. van der Speld, J. Vermaut, W. Versteeg and Y. Verzelen assisted with the set-up and maintenance of the network and data collection. We would like to thank the Flanders Marine Institute and the Royal Belgian Institute of Natural Sciences, Operational Directorate Natural Environment for infrastructure provision (RV Simon Stevin, RHIB Zeekat, RHIB Tuimelaar) and both DAB VLOOT and Rijkswaterstaat for their cooperation and the permission to use their navigation buoys. We thank the reviewers for their valuable input on the earlier version of this manuscript.

\section{Competing interests}

The authors declare that they have no competing interests.

\section{Availability of data and materials}

The datasets generated and/or analysed during the current study are available in the European Tracking Network repository, http://www.lifewatch.be/etn/.

\section{Consent for publication \\ Not applicable.}

Ethics approval and consent to participate

Not applicable.

\section{Funding}

This work was supported by data and infrastructure (RV Simon Stevin and RHIB Zeekat) provided by VLIZ and INBO as part of the Flemish contribution to LifeWatch (FWO). P. Verhelst holds a doctoral grant from the Flemish Agency of Innovation \& Entrepreneurship (VLAIO). I. van der Knaap was granted by the PCAD4Cod project.

\section{Publisher's Note}

Springer Nature remains neutral with regard to jurisdictional claims in published maps and institutional affiliations.

Received: 4 May 2018 Accepted: 5 January 2019

Published online: 23 January 2019

\section{References}

1. Block BA, Holbrook CM, Simmons SE, Holland KN, Ault JS, Costa DP, et al. Toward a national animal telemetry network for aquatic observations in the United States. Anim Biotelemetry. 2016;4(1):6.

2. Reubens J, De Rijcke M, Degraer S, Vincx M. Diel variation in feeding and activity patterns of juvenile Atlantic cod at offshore wind farms. J Sea Res. 2014;85:214-21. 
3. Winter HV, Aarts $\mathrm{G}$, van Keeken OA. Residence time and behaviour of sole and cod in the Offshore Wind farm Egmond aan Zee (OWEZ). IMARES, Wageningen YR report number: C038/10; 2010

4. Verhelst P, Buysse D, Reubens J, Pauwels I, Aelterman B, Van Hoey S, et al. Downstream migration of European eel (Anguilla anguilla L.) in an anthropogenically regulated freshwater system: implications for management. Fish Res. 2018;199:252-62.

5. Abecasis D, Afonso P, Erzini K. Can small MPAs protect local populations of a coastal flatfish, Solea senegalensis? Fish Manage Ecol. 2014:21(3):175-85.

6. Afonso P, Abecasis D, Santos RS, Fontes J. Contrasting movements and residency of two serranids in a small Macaronesian MPA. Fish Res. 2016;177:59-70

7. De Pontual H, Lalire M, Fablet R, Laspougeas C, Garren F, Martin S, et al. New insights into behavioural ecology of European seabass off the West Coast of France: implications at local and population scales. ICES J Mar Sci. 2018. https://doi.org/10.1093/icesjms/fsy086.

8. Hussey NE, Kessel ST, Aarestrup K, Cooke SJ, Cowley PD, Fisk AT, et al. Aquatic animal telemetry: a panoramic window into the underwater world. Science. 2015;348:1255642.

9. Lennox RJ, Aarestrup K, Cooke SJ, Cowley PD, Deng ZQD, Fisk AT, et al. Envisioning the future of aquatic animal tracking: technology, science, and application. Bioscience. 2017;67(10):884-96.

10. Allen AM, Singh NJ. Linking movement ecology with wildlife management and conservation. Front Ecol Evol. 2016:3:155.

11. Crossin GT, Heupel MR, Holbrook CM, Hussey NE, Lowerre-Barbieri SK, Nguyen VM, et al. Acoustic telemetry and fisheries management. Ecol Appl. 2017:27(4):1031-49.

12. Steckenreuter $A$, Hoenner $X$, Huveneers $C$, Simpfendorfer $C$, Buscot MJ, Tattersall $\mathrm{K}$, et al. Optimising the design of large-scale acoustic telemetry curtains. Mar Freshw Res. 2016;68(8):884-96.
13. Whoriskey F, Hindell M. Developments in tagging technology and their contributions to the protection of marine species at risk. Ocean Dev Int Law. 2016;47(3):221-32.

14. Reubens J, Verhelst P, van der Knaap I, Deneudt K, Moens T, Hernandez F. Environmental factors influence the detection probability in acoustic telemetry in a marine environment: results from a new setup. Hydrobiologia. 2018. https://doi.org/10.1007/s10750-017-3478-7.

15. Huisman J, Verhelst P, Deneudt K, Goethals P, Moens T, Nagelkerke $L A J$, et al. Heading south or north: novel insights on European silver eel Anguilla anguilla migration in the North Sea. Mar Ecol Prog Ser. 2016;554:257-62.

16. Abecasis D, Steckenreuter A, Reubens J, Aarestrup K, Alós J, Badalamenti $F$, et al. A review of acoustic telemetry in Europe and the need for a regional aquatic telemetry network. Anim Biotelemetry. 2018;6(1):12.

17. Breine J, Pauwels IS, Verhelst P, Vandamme L, Baeyens R, Reubens J, et al. Successful external acoustic tagging of twaite shad Alosa fallax (Lacepede 1803). Fish Res. 2017;191:36-40.

18. Verhelst P, Reubens J, Pauwels I, Buysse D, Aelterman B, Hoey S, et al. Movement behaviour of large female yellow European eel (Anguilla anguilla L.) in a freshwater polder area. Ecol Freshw Fish. 2018;27:471-80.

19. Hoenner X, Huveneers C, Steckenreuter A, Simpfendorfer C, Tattersall K, Jaine $F$, et al. Australia's continental-scale acoustic tracking database and its automated quality control process. Sci Data. 2018;5:170206.

20. Cooke SJ, Iverson SJ, Stokesbury MJW, Hinch SG, Fisk AT, VanderZwaag DL, et al. Ocean Tracking Network Canada: a network approach to addressing critical issues in fisheries and resource management with implications for ocean governance. Fisheries. 2011;36(12):583-92.

21. Cowley P, Bennett R, Childs A, Murray T. Reflection on the first five years of South Africa's Acoustic Tracking Array Platform (ATAP): status, challenges and opportunities. Afr J Mar Sci. 2017;39(4):363-72.
Ready to submit your research? Choose BMC and benefit from:

- fast, convenient online submission

- thorough peer review by experienced researchers in your field

- rapid publication on acceptance

- support for research data, including large and complex data types

- gold Open Access which fosters wider collaboration and increased citations

- maximum visibility for your research: over 100M website views per year

At BMC, research is always in progress.

Learn more biomedcentral.com/submissions 